Abstracta Iranica

Revue bibliographique pour le domaine irano-aryen

Volume 37-38-39 | 2018

Comptes rendus des publications de 2014-2016

\title{
Juanjo Ferrer-Losilla. Final -y in Non-Manichaean Parthian and the Proto-Parthian 'Rhytmic Law'
}

\section{Agnes Korn}

\section{(2) OpenEdition}

1 Journals

\section{Édition électronique}

URL : http://journals.openedition.org/abstractairanica/47374

DOI : 10.4000/abstractairanica.47374

ISBN : 1961-960X

ISSN : 1961-960X

Éditeur :

CNRS (UMR 7528 Mondes iraniens et indiens), Éditions de l'IFRI

Référence électronique

Agnes Korn, « Juanjo Ferrer-Losilla. Final -y in Non-Manichaean Parthian and the Proto-Parthian 'Rhytmic Law'», Abstracta Iranica [En ligne], Volume 37-38-39 | 2018, document 15, mis en ligne le 30 décembre 2018, consulté le 28 septembre 2020. URL : http://journals.openedition.org/abstractairanica/47374 ; DOI : https://doi.org/10.4000/abstractairanica.47374

Ce document a été généré automatiquement le 28 septembre 2020

Tous droits réservés 


\title{
Juanjo Ferrer-Losilla. Final -y in Non- Manichaean Parthian and the Proto- Parthian 'Rhytmic Law'
}

\author{
Agnes Korn
}

\section{RÉFÉRENCE}

Juanjo Ferrer-Losilla. Final -y in Non-Manichaean Parthian and the Proto-Parthian 'Rhytmic Law'. Paris : Association pour l'Avancement des études iraniennes, 2014, 108p. (Cahiers de Studia Iranica 52)

1 Déjà par son titre, le présent ouvrage s'annonce comme étant un parallèle au travail effectué par Philip Huyse sur le moyen-perse (Le y final dans les inscriptions moyen-perses et la 'loi rythmique' proto-moyen-perse, Paris, 2003, Cahiers de Studia Iranica 29 http:// www.peeters-leuven.be/boekoverz.asp?nr=7610), tous les deux s'intéressant à la question de l'origine de la lettre "yod» au final de certains mots en moyen-perse et parthe épigraphiques, ainsi qu'à la distribution de ce yod dans les deux langues moyens-iraniennes occidentales. Le sujet a suscité une vive discussion tout au long de l'histoire de la linguistique iranienne, mais les recherches se sont pour la plupart concentrées sur le moyen-perse dont la documentation est plus riche et l'interprétation duquel profite en outre de l'existence d'une langue dont il provient (le vieux-perse) et d'une langue moderne (le persan) qui dérive d'un dialecte moyen-perse, tandis qu'une telle situation n'est pas le cas pour le parthe.

2 Pour le moyen-perse, Huyse 2003 avait conclu qu'un yod était suffixé à des mots monosyllabiques ainsi qu'à des mots polysyllabiques dont la syllabe finale est légère (il n'y a donc pas de yod final après des mots polysyllabiques à finale lourde), mais que la distribution en parthe ne semblait pas être la même. S'appuyant sur l'approche d'Huyse, l'A. a entrepris la collecte et la classification des mots parthes épigraphiques 
selon leur nombre de syllabes et le poids de celles-ci, et retrace le développement de la flexion nominale parthe pour expliquer la distribution du yod final.

3 Contrairement au moyen-perse, il n'y a pas de yod final ajouté à des formes verbales parthes (exception faite de la désinence optative -ēndē). Aussi contrairement au moyenperse, seuls les noms monosyllabiques légers prennent un yod final, à quelques exceptions près (p. 41). Quant aux polysyllabiques, ceux ayant une syllabe finale lourde n'affichent pas de yod, alors que ceux à finale légère l'ont en général (p. 57f., 63). L'A. avance aussi des explications pour les cas qui ne se plient pas à cette distribution.

4 Tous ceux qui s'intéressent à l'épigraphie parthe et à la grammaire historique de cette langue tireront profit du présent ouvrage, qui a aussi le mérite de bien signaler les cas pour lesquels on n'a pas encore trouvé d'explication.

\section{AUTEURS}

\section{AGNES KORN}

CNRS, Mondes iranien et indien, Paris 